\title{
CRESCIMENTO E NUTRIÇÃO DE CLONE DE EUCALIPTO EM RESPOSTA À APLICAÇÃO DE CONCENTRAÇÕES DE C-ÁCIDO HÚMICO(1)
}

\author{
Gabriela Lúcia Pinheiro ${ }^{(2)}$, Carlos Alberto Silva ${ }^{(3)}$ \& Antônio \\ Eduardo Furtini Neto ${ }^{(4)}$
}

\begin{abstract}
RESUMO
Os efeitos das substâncias húmicas nas propriedades dos solos são conhecidos, porém poucos são os estudos que avaliam os efeitos desses materiais nas plantas; assim, dependendo da concentração e da natureza química das moléculas húmicas aplicadas, pode haver maior expansão radicular, incremento na absorção de nutrientes e maior crescimento das culturas. Com o objetivo de avaliar os efeitos de concentrações de C-ácido húmico na nutrição e no crescimento de mudas de eucalipto, foi realizado um experimento em solução nutritiva, em casa de vegetação. Os tratamentos constituíram-se de duas fontes de ácidos húmicos (material húmico - MH e ácido húmico p.a. - AH p.a.), sendo cada fonte adicionada na solução nutritiva nas seguintes concentrações de C-ácido húmico: $0,10,30$ e $150 \mathrm{mg} \mathrm{L}^{-1}$. Outros tratamentos foram também testados, utilizando-se a fonte $\mathrm{AH}$ p.a. nas concentrações de $0,10,30$ e $150 \mathrm{mg} \mathrm{L}^{-1} \mathrm{C}$-ácido húmico, acrescidas de $21 \mathrm{mg} \mathrm{L}^{-1}$ de ácido cítrico e $9 \mathrm{mg} \mathrm{L}^{-1}$ de ácido oxálico. Foram analisados a condutividade eletrolítica na solução nutritiva, diâmetro do caule e altura das plantas, matéria seca de caule, de folhas, da parte aérea, da raiz e total, relação matéria seca de raiz:parte aérea, acúmulo de nutrientes no caule e nas folhas. A altura e o diâmetro de caule diminuíram linearmente com a aplicação de concentrações de C-ácido húmico da fonte $\mathrm{AH}$ p.a. A utilização do $\mathrm{MH}$, em baixas concentrações de $\mathrm{C}$-ácido húmico $\left(0,07-4,3 \mathrm{mg} \mathrm{L}^{-1}\right)$, propiciou a máxima produção de matéria seca de raiz, caule, folha e total. O maior acúmulo de alguns nutrientes (principalmente N, P e B) resultou, em alguns tratamentos, em reduzidos incrementos $(2,4$ a $9,3 \%)$ nas produções de matéria seca de raiz, folha, caule e total; assim, não é aconselhável, em solução nutritiva, a aplicação das fontes de ácidos húmicos utilizadas neste estudo para o cultivo de mudas de eucalipto.
\end{abstract}

Termos de indexação: substâncias húmicas, ácido cítrico, ácido oxálico, crescimento radicular, complexos organometálicos.

\footnotetext{
(1) Parte da Dissertação de Mestrado do primeiro autor apresentada ao Programa de Pós-Graduação em Ciência do Solo, Departamento de Ciência do Solo, Universidade Federal de Lavras - UFLA. Recebido para publicação em agosto de 2009 e aprovado em maio de 2010.

(2) Doutoranda do Programa de Pós-Graduação em Ciência do Solo, Departamento de Ciência do Solo, Universidade Federal de Lavras - UFLA. Caixa Postal 37, CEP 37200-000 Lavras (MG). E-mail: gabiquimica8@yahoo.com.br

(3) Professor do Departamento de Ciência do Solo, UFLA. E-mail: csilva@dcs.ufla.br

(4) Professor do Departamento de Ciência do Solo, UFLA. E-mail: afurtini@dcs.ufla.br
} 


\title{
SUMMARY: GROWTH AND NUTRITION OF EUCALYPTUS CLONE AS AFFECTED BY THE APPLICATION OF C-HUMIC ACID DOSES
}

\begin{abstract}
The effects of humic substances on soil properties are known. However, little is known about the effects of these materials on plants. Depending on the concentration and chemical nature of the humic molecules applied, the effect may be expressed by an expansion of the root system, increase of nutrient absorption and increased crop growth. To evaluate the effects of $C$ humic acid concentrations on nutrition and growth of eucalyptus seedlings, a greenhouse experiment was carried out in nutrient solution. The treatments consisted of two sources of humic acids (humic material - HM and humic acid p.a.-HA p.a). Each source was applied at four C-humic acid concentrations: 0, 10, 30, and $150 \mathrm{mg} \mathrm{L}^{-1}$. Other treatments were applied using the source HA p.a. at concentrations of $0,10,30$, and $150 \mathrm{mg} \mathrm{L}^{-1}$ of C-humic acid combined with $21 \mathrm{mg} \mathrm{L}^{-1}$ citric acid and $9 \mathrm{mg} \mathrm{L}^{-1}$ oxalic acid. The following variables were analyzed: electric conductivity of the nutrient solution, stem diameter and plant height, dry matter of stem, leaves, shoot, root and total, dry matter root:shoot ratio, and nutrient accumulation in leaves and stem. Plant height and stem diameter decreased linearly with concentrations of C-humic acid of HA p.a. The use of HM at low concentrations of C-humic acid (0.07-4.3 $\left.\mathrm{mg} \mathrm{L}^{-1}\right)$ resulted in maximum root, stem, leaf and total dry matter production. The greatest accumulation of some nutrients (especially $N, P$, and B) resulted, in some treatments, in small increases (2.4 to $9.3 \%$ ) of root, leaf, stem and total dry matter production. The application of the humic acid sources in nutrient solution, as used in this study for the cultivation of eucalyptus seedlings, is therefore not recommended.
\end{abstract}

Index terms: humic substances, citric acid, oxalic acid, root growth, organicmetallic complexes.

\section{INTRODUÇÃO}

As substâncias húmicas ( $\mathrm{SHs})$ constituem o produto final de decomposição de resíduos orgânicos e representam o principal componente da matéria orgânica em água, solos e sedimentos. Essa classe de compostos engloba materiais coloidais do tipo ácido fúlvico, ácido húmico e humina, em um esquema simplificado de classificação; trata-se de classes de moléculas que possuem variação em cor, grau de condensação e massa molar e que apresentam anéis aromáticos e grupos funcionais com potencial de desenvolvimento de cargas elétricas (Vaughan et al., 1985). São várias as funções que as $\mathrm{SHs}$ exercem nas propriedades químicas, físicas e biológicas do solo (Stevenson, 1994); além disso, interferem em processos fisiológicos das plantas, na absorção de nutrientes e no crescimento radicular e da parte aérea de diferentes espécies vegetais (Chen \& Aviad, 1990; Nardi et al., 2002).

$\mathrm{O}$ estudo da ação direta das $\mathrm{SHs}$ sobre o metabolismo e o crescimento das plantas tem se concentrado principalmente na ação dos ácidos fúlvicos, pelo fato de essas moléculas possuírem menor massa molar que a fração ácido húmico, podendo, desse modo, acessar mais facilmente possíveis receptores na superfície da membrana plasmática ou no interior da célula (Vaughan et al., 1985). Entretanto, há relatos do emprego de ácidos húmicos no cultivo de gramíneas e de hortaliças (Cooper et al., 1998; Ribeiro et al., 2000), sendo a ação deles sobre as culturas similar às funções desempenhadas por moléculas de menor massa molar (Canellas et al., 2006).
Os ácidos húmicos, que se constituem na fração reativa mais estável das SHs, têm coloração escura, alto teor de anéis aromáticos, grupos funcionais hidrofílicos contendo oxigênio, além de possuírem as mais diversas estruturas e composições elementares, as quais se mostram dependentes de suas fontes de origem e método de extração (Guerra et al., 2008). Assim, a resposta das plantas às $\mathrm{SH}$ é dependente do tipo de matéria-prima utilizada na extração desses compostos, da massa molar dos eletrólitos húmicos extraídos e, sobretudo, da espécie vegetal estudada (Santos et al., 2008). Matérias-primas orgânicas diversas têm em sua composição ácidos húmicos e fúlvicos de massas molares e composição química diferentes, bem como distintas concentrações desses ácidos, os quais podem causar efeitos variáveis nas plantas (Brun, 1993).

Até determinadas concentrações, os ácidos húmicos podem favorecer o desenvolvimento de plantas, alterando tanto a parte aérea quanto as raízes (Rodda et al., 2006; Rosa et al., 2009), sendo os efeitos difíceis de ser explicados, devido à natureza complexa e ainda desconhecida dessa fração húmica; é possível que os ácidos húmicos possam exercer inúmeros efeitos nas plantas e que alguns destes possam resultar, direta ou indiretamente, em uma regulação da absorção de íons (Nardi et al., 2002). Segundo Maggioni et al. (1987), os ácidos húmicos podem influenciar a absorção de nutrientes via efeito enzimático, por intermédio da atividade de ATPase dependente de potássio (K) e magnésio (Mg). Fernández-Escobar et al. (1996) também mostraram a influência positiva da aplicação de ácidos húmicos na absorção de $\mathrm{K}, \mathrm{Mg}, \mathrm{Ca}, \mathrm{B}$ e Fe. 
Apesar de já terem sido realizados alguns estudos em que foram utilizados ácidos húmicos de diversas fontes, para diferentes culturas, não foram encontrados estudos para o eucalipto. Considerandose que o sucesso do estabelecimento dos povoamentos florestais depende de vários fatores, dentre os quais a formação de mudas de qualidade tem papel preponderante, a aplicação de ácido húmico pode ser útil, pois os efeitos positivos desse tipo de aplicação têm sido relatados para diversas culturas.

A liberação de exsudatos radiculares, como ácidos cítrico, butírico, málico e oxálico, pode modificar o arranjo supramolecular dos ácidos húmicos, o que implica disponibilização de subunidades bioativas que estimulam o desenvolvimento vegetal (Façanha et al., 2002; Canellas et al., 2005), daí a necessidade de se testar a combinação de doses de ácidos húmicos com ácidos orgânicos - no caso deste estudo, o ácido cítrico (AC) e o ácido oxálico (AO). Nesse contexto, tem-se como hipótese que a aplicação de ácidos húmicos, principalmente com ácidos orgânicos de baixa massa molar, pode favorecer a formação de complexos organometálicos de menor massa, o que pode implicar maior absorção desses complexos pelas plantas, incremento do conteúdo de nutrientes e melhor desenvolvimento das mudas de eucalipto. Espera-se que a aplicação de ácidos húmicos resulte em maior acúmulo de nutrientes pelo eucalipto, estimule o crescimento de raízes e da parte aérea e que exista uma concentração ideal de C-ácido húmico para a cultura. Por se tratar de solução nutritiva, um meio pouco tamponado, a formação de complexos húmicometálicos de alta massa molar, ou de elevada estabilidade química, pode, por outro lado, interferir de modo negativo no crescimento das mudas, em função da baixa entrada ou do aproveitamento de nutrientes desses complexos nas células das raízes.

Objetivou-se avaliar o efeito de concentrações de C-ácido húmico, na presença ou não de $\mathrm{AC}$ e $\mathrm{AO}$, no crescimento, na produção de matéria seca e no acúmulo de nutrientes em mudas de eucalipto cultivadas em solução nutritiva.

\section{MATERIAL E MÉTODOS}

\section{Montagem do experimento}

Foram utilizadas mudas de eucalipto (Eucalyptus urograndis) com 30 dias de idade, em um experimento com solução nutritiva, realizado em casa de vegetação, utilizando-se como tratamentos concentrações de Cácido húmico obtidas a partir de um material húmico de origem comercial rico em ácido húmico $(\mathrm{MH})$ e de um ácido húmico puro para análise (AH p.a.). Cada fonte de ácido húmico foi adicionada à solução nutritiva em quatro concentrações de C-ácido húmico $(0,10,30$ e $150 \mathrm{mg} \mathrm{L}^{-1}$ ). Outros tratamentos foram aplicados, utilizando-se a fonte $\mathrm{AH}$ p.a., nas concentrações de 0 ,
10, 30 e $150 \mathrm{mg} \mathrm{L}^{-1} \mathrm{C}$-ácido húmico combinadas com $21 \mathrm{mg} \mathrm{L}^{-1}$ de ácido cítrico-AC e $9 \mathrm{mg} \mathrm{L}^{-1}$ de ácido oxálico-AO (AH p.a. + AC + AO). O delineamento estatístico foi em blocos ao acaso, com 12 tratamentos e três repetições, totalizando 36 parcelas experimentais. As características físicas e químicas das fontes de ácidos húmicos utilizadas no estudo são apresentadas no quadro 1.

As mudas obtidas de viveiro comercial, e em tubetes, para adaptação, foram transferidas para bandejas plásticas contendo $36 \mathrm{~L}$ de solução nutritiva de Clark (1975), com um quarto da força iônica, que foi aumentada semanalmente em $25 \%$, até atingir 100 \% da força iônica original. Após três semanas nesse sistema, as mudas foram transferidas para uma solução nutritiva com $100 \%$ da força iônica, que continha: $2,53 \mathrm{mmol} \mathrm{L}^{-1}$ de $\mathrm{Ca}\left(\mathrm{NO}_{3}\right)_{2} 4 \mathrm{H}_{2} \mathrm{O}$; $1,30 \mathrm{mmol} \mathrm{L}^{-1}$ de $\mathrm{KNO}_{3} ; 0,50 \mathrm{mmol} \mathrm{L}^{-1}$ de $\mathrm{KCl}$; $0,90 \mathrm{mmol} \mathrm{L}^{-1}$ de $\mathrm{NH}_{4} \mathrm{NO}_{3} ; 0,60 \mathrm{mmol} \mathrm{L}^{-1}$ de $\mathrm{MgSO}_{4} 7$ $\mathrm{H}_{2} \mathrm{O} ; 1,50 \mathrm{mmol} \mathrm{L}^{-1}$ de $\mathrm{Ca}\left(\mathrm{H}_{2} \mathrm{PO}_{4}\right) \quad \mathrm{H}_{2} \mathrm{O}$; $1,00 \mathrm{mmol} \mathrm{L}^{-1}$ de $\mathrm{MgCl}_{2}, 4 \mathrm{H}_{2} \mathrm{O} .7 \mu \mathrm{mol} \mathrm{L}-1$ de $\mathrm{MnCl}_{2}$. $4 \mathrm{H}_{2} \mathrm{O} ; 19 \mu \mathrm{mol} \mathrm{L}^{-1}$ de $\mathrm{H}_{3} \mathrm{BO}_{3} ; 2 \mu \mathrm{mol} \mathrm{L}-1$ de $\mathrm{ZnSO}_{4}$. $7 \mathrm{H}_{2} \mathrm{O} ; 0,086 \mu \mathrm{mol} \mathrm{L}^{-1} \mathrm{de}\left(\mathrm{NH}_{4}\right)_{6} \mathrm{MoO} . \mathrm{H}_{2} \mathrm{O}$; $0,5 \mu \mathrm{mol} \mathrm{L}^{-1}$ de $\mathrm{CuSO}_{4}, 5 \mathrm{H}_{2} \mathrm{O}$; e $38 \mu \mathrm{mol} \mathrm{L}^{-1}$ de FeEDTA, sendo todos os reagentes p.a.

Após o período de adaptação, as plantas foram individualizadas em vasos plásticos com capacidade para 3,6 L, nos quais foram aplicados os tratamentos. Durante todo o período experimental (55 dias), a solução recebeu aeração constante; além disso,

Quadro 1. Atributos químicos e físicos dos materiaisfonte de ácidos húmicos

\begin{tabular}{|c|c|c|}
\hline \multirow{2}{*}{ Atributo } & \multicolumn{2}{|c|}{ Produto } \\
\hline & MH & AH p.a. \\
\hline Densidade $\left(\mathrm{g} \mathrm{mL}^{-1}\right)$ & 1,17 & -- \\
\hline $\mathrm{pH}$ & 10,5 & 5,3 \\
\hline Condutividade eletrolítica ( $\left.\mathrm{dS} \mathrm{m}^{-1}\right)$ & 35,0 & 17,4 \\
\hline Carbono orgânico total $\left(\mathrm{g} \mathrm{kg}^{-1}\right)^{(1)}$ & 62,8 & 542,6 \\
\hline C-ácido húmico $\left(\mathrm{g} \mathrm{kg}^{-1}\right)^{(2)}$ & 7,9 & 81,0 \\
\hline N-total $\left(\mathrm{g} \mathrm{kg}^{-1}\right)^{(3)}$ & 22,2 & 46,0 \\
\hline $\mathrm{P}\left(\mathrm{g} \mathrm{kg}^{-1}\right)^{(4)}$ & 5,4 & 1,3 \\
\hline $\mathrm{K}\left(\mathrm{g} \mathrm{kg}^{-1}\right)^{(5)}$ & 9,2 & 0,4 \\
\hline $\mathrm{Ca}\left(\mathrm{g} \mathrm{kg}^{-1}\right)^{(6)}$ & n.d & n.d \\
\hline $\operatorname{Mg}\left(\mathrm{g} \mathrm{kg}^{-1}\right)^{(6)}$ & n.d & n.d \\
\hline $\mathrm{S}\left(\mathrm{g} \mathrm{kg}^{-1}\right)^{(7)}$ & 0,4 & 11,8 \\
\hline $\mathrm{Na}\left(\mathrm{g} \mathrm{kg}^{-1}\right)^{(5)}$ & 0,7 & 69,0 \\
\hline $\mathrm{B}\left(\mathrm{mg} \mathrm{kg}^{-1}\right)^{(4)}$ & 46,0 & 23,4 \\
\hline $\mathrm{Cu}\left(\mathrm{mg} \mathrm{kg}^{-1}\right)^{(6)}$ & 4,4 & 13,2 \\
\hline $\mathrm{Fe}\left(\mathrm{mg} \mathrm{kg}^{-1}\right)^{(6)}$ & 430,0 & 965 \\
\hline $\operatorname{Mn}\left(\mathrm{mg} \mathrm{kg}^{-1}\right)^{(6)}$ & 3,4 & 14,5 \\
\hline $\mathrm{Zn}\left(\mathrm{mg} \mathrm{kg}^{-1}\right)^{(6)}$ & 6,3 & 32,2 \\
\hline
\end{tabular}

(1) Oxidação com dicromato (Yeomans \& Bremner, 1988). ${ }^{(2)}$ Teor de carbono na forma de ácidos húmicos (Benites et al., 2003). (3) Destilação a vapor após digestão (Kjeldhal) com ácido sulfúrico e mistura catalítica. ${ }^{(4)}$ Colorimetria. ${ }^{(5)}$ Fotometria de emissão de chama. ${ }^{(6)}$ Espectrofotometria de absorção atômica.

(7) Turbidimetria; nd: não detectável. $\mathrm{MH}$ : material húmico; $\mathrm{AH}$ p.a.: ácido húmico puro para análise. 
procedia-se à troca da solução e à reposição das concentrações de C-ácido húmico nos tratamentos pertinentes, a cada 15 dias. Durante o intervalo de renovação das soluções, o volume dos vasos foi completado, sempre que necessário, utilizando-se água desionizada, sendo o $\mathrm{pH}$ corrigido diariamente para $5,5( \pm 0,2)$, com a adição de solução de $\mathrm{KOH}$ ou de $\mathrm{HCl}, 0,5 \mathrm{~mol} \mathrm{~L}^{-1}$.

\section{Atributos analisados}

Após 55 dias de cultivo das mudas, foram efetuadas as medições de altura, utilizando-se uma fita métrica, e do diâmetro do caule, por meio de paquímetro digital. O material vegetal foi colhido, lavado em água destilada e separado em raízes, caules e folhas, que, posteriormente, foram acondicionados separadamente em sacos de papel, secos em estufa com circulação forçada de ar a $65-70{ }^{\circ} \mathrm{C}$ e pesados em balança de precisão $(0,01 \mathrm{~g})$, para obtenção da matéria seca.

As análises dos teores de nutrientes nos tecidos vegetais foram realizadas pelos métodos descritos em Malavolta et al. (1997). Relacionando-se os teores dos nutrientes com a matéria seca produzida no caule e nas folhas, foi determinado o acúmulo de $\mathrm{N}, \mathrm{P}, \mathrm{K}, \mathrm{Ca}$, $\mathrm{Mg}, \mathrm{S}, \mathrm{Fe}, \mathrm{Zn}, \mathrm{Cu}, \mathrm{B}$ e Mn no tecido vegetal.

A medição da condutividade eletrolítica na solução nutritiva foi realizada após cada troca de solução, utilizando-se para isso um condutivímetro portátil.

De posse das concentrações de C-ácido húmico das fontes testadas, bem como dos teores de nutrientes de cada fonte de ácido húmico (Quadro 1), foi calculada a carga de nutrientes adicionada à solução nutritiva em razão dos tratamentos avaliados (Quadro 2).

\section{Análise estatística}

Os dados obtidos foram submetidos à análise de variância e de regressão, com o nível de significância de $5 \%$, sendo empregado, nessa etapa, o programa estatístico SISVAR (Ferreira, 2003).

\section{RESULTADOS E DISCUSSÃO}

\section{Crescimento e produção de matéria seca}

A adição de ácidos húmicos diminuiu linearmente a altura da planta e o diâmetro do caule para os tratamentos AH p.a. e AH p.a. + AC + AO (Figura 1a,b). As alturas máxima e mínima estimadas foram, respectivamente, de $65,6 \mathrm{~cm}$ na concentração de 6,54 $\mathrm{mg} \mathrm{L}^{-1}$ de C-ácido húmico e $30,5 \mathrm{~cm}$ na concentração de $150 \mathrm{mg} \mathrm{L}^{-1}$ de C-ácido húmico, com a utilização do MH (Figura 1a). No estudo de Atiyeh et al. (2002), a aplicação de $200 \mathrm{mg} \mathrm{kg}^{-1}$ de humato extraído de vermicomposto propiciou a maior altura de plântulas de tomate; contudo, para obtenção da maior área foliar de tomateiro, foi necessário maior aplicação de humato, visto que a dose requerida para isso foi de $500 \mathrm{mg} \mathrm{kg}^{-1}$.

Com base no modelo raiz quadrada de regressão ajustado $\left(\hat{\mathrm{y}}=9,854-0,048 \mathrm{MH}+0,222 \mathrm{MH}^{0,5} \mathrm{R}^{2}=\right.$ $\left.0,94^{* *}\right)$, estimou-se que o maior diâmetro do caule $(10,1$ $\mathrm{mm}$ ) foi obtido na concentração de $4,3 \mathrm{mg} \mathrm{L}^{-1}$ de Cácido húmico, sendo esse valor reduzido praticamente à metade na concentração de $150 \mathrm{mg} \mathrm{L}^{-1}$ de C-ácido húmico, ambos com a utilização do MH (Figura 1b). A maioria das respostas das plantas à aplicação de SHs, em geral, apresenta um padrão típico de maior crescimento em função do aumento progressivo das concentrações, havendo redução do crescimento para as concentrações mais elevadas de $\mathrm{SHs}$ (Ayuso et al., 1996; Atiyeh et al., 2002). Chen \& Aviad (1990) compilaram os resultados de promoção de crescimento vegetal induzido por $\mathrm{SHs}$ e verificaram que a concentração adequada de ácidos húmicos e fúlvicos, quando aplicados em solução nutritiva, varia de 25 a $300 \mathrm{mg} \mathrm{L}^{-1}$, para as diferentes plantas examinadas.

O acúmulo de matéria seca de raiz, caule, folha e total mostraram decréscimos curvilineares com taxas raízes quadráticas, em função do aumento das concentrações de C-ácido húmico do $\mathrm{MH}$ (Figura 2). Por meio da equação de regressão ajustada

Quadro 2. Cargas de nutrientes e de sódio adicionadas à solução nutritiva em função dos materiais utilizados como fontes de ácidos húmicos

\begin{tabular}{|c|c|c|c|c|c|c|c|c|c|c|}
\hline $\begin{array}{l}\text { Concentração de } \\
\text { C-ácido húmico }\end{array}$ & $\mathbf{N}$ & $\mathbf{P}$ & $\mathbf{K}$ & $\mathbf{S}$ & $\mathbf{N a}$ & B & $\mathrm{Cu}$ & $\mathbf{F e}$ & Mn & Zn \\
\hline \multirow[t]{2}{*}{$\mathrm{mg} \mathrm{L}^{-1}$} & & & - mg L & & & & & $-\mu g \mathrm{~L}^{-1}$ & & \\
\hline & \multicolumn{10}{|c|}{ Material húmico - MH } \\
\hline 0 & 25 & 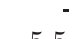 & - & - & e & 20 & $55^{-}$ & - & - & 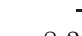 \\
\hline 10 & 25 & 5,5 & 11,1 & 0,5 & 0,8 & 50 & 5,5 & 520 & 2,7 & 8,3 \\
\hline 30 & 75 & 16,5 & 33,3 & 1,5 & 2,4 & 150 & 16,5 & 1.560 & 8,1 & 24,9 \\
\hline 150 & 375 & 82,5 & 166,5 & 7,5 & 12 & 750 & 80 & 7.800 & 40 & 124,5 \\
\hline \multicolumn{11}{|c|}{ Ácido húmico puro para análise - $\mathrm{AH}$ p.a. } \\
\hline 10 & 5,5 & 0,1 & 0,05 & 1,4 & 8,5 & 2,9 & 1,6 & 116,7 & 1,8 & 4 \\
\hline 30 & 16,5 & 0,4 & 0,15 & 4,2 & 25,8 & 8,7 & 4,8 & 350,1 & 5,4 & 12 \\
\hline 150 & 82,5 & 2,1 & 0,75 & 21 & 127,5 & 42,9 & 24 & 1.750 & 27 & 60 \\
\hline
\end{tabular}




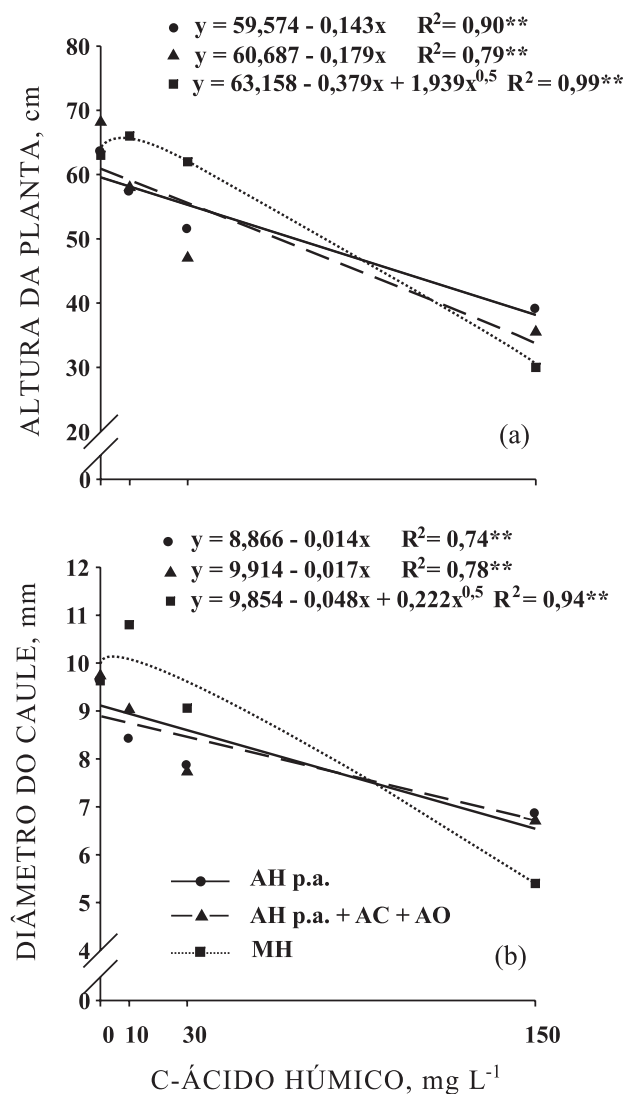

Figura 1. Altura da planta (a) e diâmetro do caule (b) de mudas de eucalipto em resposta ao aumento de concentrações de C-ácido húmico em solução nutritiva. AH p.a.: ácido húmico p.a.; MH: material húmico; AC: ácido cítrico; AO: ácido oxálico.

$\left(\hat{\mathrm{y}}=9,393-0,061 \mathrm{AH}+0,238 \mathrm{AH}^{0,5} \mathrm{R}^{2}=0,84^{* *}\right)$, estimou-se a produção máxima de matéria seca de raiz (9,6 g/planta), sendo esta obtida utilizando-se $3,8 \mathrm{mg} \mathrm{L}^{-1}$ de C-ácido húmico do MH (Figura 2a); além disso, verificou-se que as menores concentrações de ácidos húmicos promoveram raízes altamente ramificadas. Isso resulta em elevada área de superfície radicular, que pode contribuir para a absorção mais eficiente de nutrientes, fato também observado por Nikbakht et al. (2008), ao avaliarem o crescimento de gérbera em solução nutritiva contendo $1.000 \mathrm{mg} \mathrm{L}^{-1}$ de ácido húmico. Vaughan et al. (1985) também notaram efeitos positivos no crescimento radicular do trigo cultivado em solução com $50 \mathrm{mg} \mathrm{L}^{-1}$ de ácidos húmicos. Tendo em vista esses resultados, é difícil estabelecer a concentração ideal de ácidos húmicos para a maioria das culturas, uma vez que as respostas das plantas são dependentes do meio de cultivo testado, do modo de aplicação dos ácidos húmicos, bem como das espécies e fontes de SHs avaliadas.

A ação promotora do crescimento radicular que as SHs possuem está bem documentada (Cooper et al., 1998; Silva et al., 1999; Costa, 2001; Canellas et al.,
2002; Canellas et al., 2004; Rodda et al., 2006; Marques Júnior et al., 2008; Baldotto et al., 2009; Rosa et al., 2009); entretanto, não são comuns trabalhos que relatam os efeitos dessas frações humificadas sobre as diversas partes da planta. A utilização do MH, em baixas concentrações de C-ácido húmico $\left(0,07-1,5 \mathrm{mg} \mathrm{L}^{-1}\right)$, aumentou a produção de matéria seca de caule $(2,4 \%)$, folhas $(3,1 \%)$ e total $(3,3 \%)$ (Figura $2 b, c, d)$; além disso, verificou-se que a queda na produção de matéria seca foi mais pronunciada com a utilização desta fonte, em relação ao AH p.a. Na concentração de $150 \mathrm{mg} \mathrm{L}^{-1}$ de C-ácido húmico do $\mathrm{MH}$, as produções de matéria seca de raiz, caule, folha e total foram inferiores às obtidas, na mesma concentração, com o AH p.a. Isso pode estar relacionado com o excesso ou desbalanço de nutrientes adicionados na solução nutritiva, principalmente no tratamento com o MH (Quadro 2). As fontes de ácidos húmicos testadas possuem, em sua composição, distintos teores de C-ácido húmico e elementos químicos (Quadro 1), e as concentrações de ácidos húmicos foram estabelecidas com base nos teores de C-ácido húmico em cada material, daí a maior adição de nutrientes (exceto $\mathrm{Se} \mathrm{Na}$ ) pelo MH (Quadro 2).

Ayuso et al. (1998) atribuíram a queda no rendimento da cevada, nas concentrações mais elevadas de $\mathrm{SHs}_{\mathrm{s}}\left(100 \mathrm{mg} \mathrm{L}^{-1} \mathrm{C}\right)$, à diminuição dos teores de micronutrientes na solução nutritiva provocada pelo excesso de quelantes, o que, possivelmente, resultou na formação de complexos organometálicos de alta massa molar, impedindo a absorção destes pelas plantas. Neste estudo, a queda na produção de matéria seca, verificada principalmente nas maiores concentrações de C-ácido húmico (Figura 2), não pode ser atribuída à baixa disponibilidade de micronutrientes, e sim ao excesso desses elementos na solução nutritiva, causando, possivelmente, toxidez nas plantas (Quadro 2).

$\mathrm{O}$ valor ótimo de condutividade eletrolítica em substratos para cultivos de plantas de eucalipto situase na faixa de 0,76 a $1,25 \mathrm{dS} \mathrm{m}^{-1}$, na relação substrato:água de 1:2 (Lopes et al., 2008). A faixa de variação de condutividade eletrolítica obtida na solução nutritiva foi de 1,13 a $1,57 \mathrm{dS} \mathrm{m}^{-1}$ (Figura 3), e esses valores são maiores do que os recomendados, o que justifica, entre outros fatores condicionantes, os decréscimos em produção de matéria seca do eucalipto com as concentrações de C-ácido húmico (Figura 2).

Não houve efeito significativo de concentrações de C-ácido húmico da fonte $\mathrm{AH}$ p.a. na relação matéria seca de raiz/parte aérea. Entretanto, verificou-se acréscimo linear da relação raiz/parte aérea com o aumento das concentrações de C-ácido húmico do $\mathrm{MH}$ (Figura 4). Nos tratamentos AH p.a. + AC + AO também houve aumento na relação raiz/parte aérea até concentrações próximas de 70-80 $\mathrm{mg} \mathrm{L}^{-1}$ de C-ácido húmico. Esses resultados estão de acordo com os de outros autores que também observaram efeito maior das SHs no crescimento das raízes do que da parte 

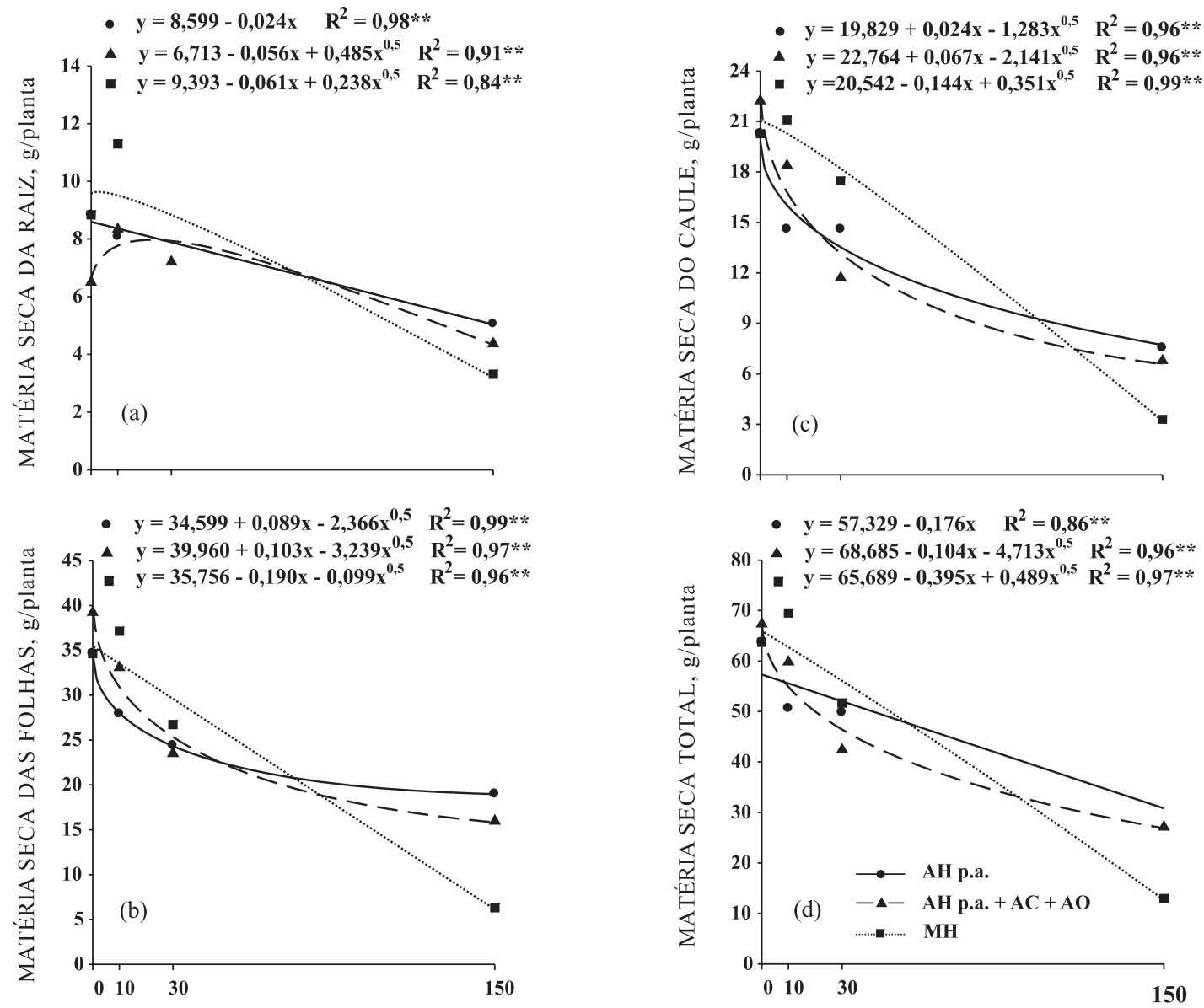

C-ÁCIDO HÚMICO, $\mathrm{mg} \mathrm{L}^{-1}$

Figura 2. Matéria seca de raiz (a), folhas (b), caule (c) e total (d) de mudas de eucalipto em resposta ao aumento de concentrações de C-ácido húmico em solução nutritiva. AH p.a.: ácido húmico p.a.; MH: material húmico; AC: ácido cítrico; AO: ácido oxálico.

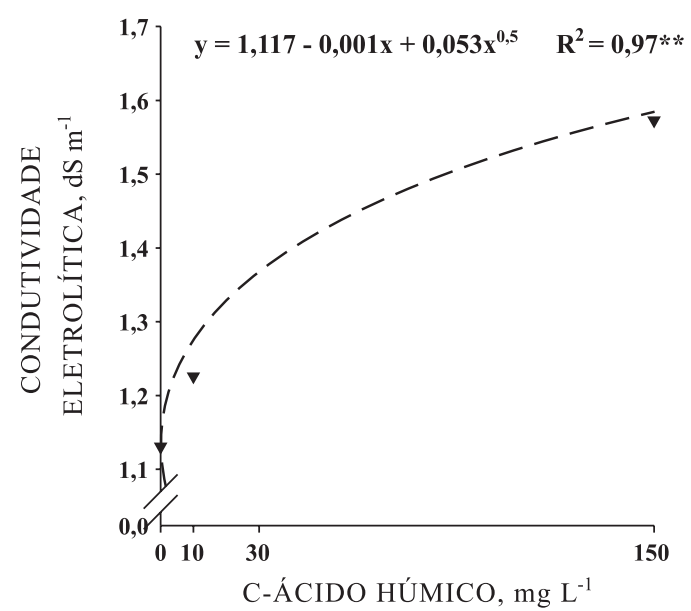

Figura 3. Condutividade eletrolítica na solução nutritiva, em função da aplicação de concentrações de C-ácido húmico.

aérea (Adani et al., 1998; Atiyeh et al., 2002; Turkmen, 2004; Nikbakht et al., 2008). Segundo Nikbakht et al. (2008), uma possível explicação para os resultados

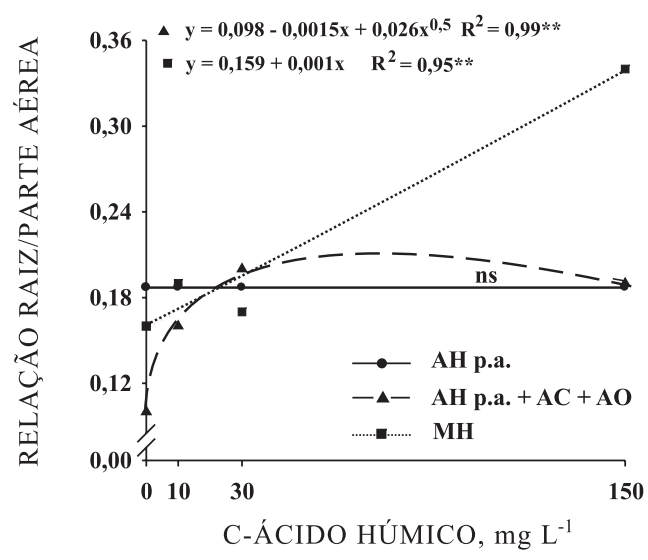

Figura 4. Razão matéria seca de raiz/parte aérea de mudas de eucalipto em resposta ao aumento de concentrações de C-ácido húmico em solução nutritiva. AH p.a.: ácido húmico p.a.; MH: material húmico; AC: ácido cítrico; AO: ácido oxálico; ns: não significativo.

obtidos seria uma maior alocação de nutrientes e fotoassimilados para as raízes do que para as folhas. 


\section{Acúmulo de macronutrientes}

Com base nas equações de regressão, observou-se que o acúmulo de $\mathrm{N}$ na folha e no caule aumentou, respectivamente, até as concentrações de 12 e $27 \mathrm{mg} \mathrm{L}^{-1}$ de C-ácido húmico do $\mathrm{MH}$, com diminuição a partir desses valores (Figura 5a,d). Nas concentrações citadas, possivelmente, o meio de cultivo encontravase em condições adequadas para promover os maiores acúmulos de N. Ayuso et al. (1996) também verificaram que concentrações em torno de $5 \mathrm{mg} \mathrm{L}^{-1}$ de $\mathrm{SHs}$ proporcionaram maiores teores de $\mathrm{N}$ na parte aérea de cevada. Nos tratamentos em que a fonte $\mathrm{AH}$ p.a. foi utilizada, não foram observados acréscimos no acúmulo de macronutrientes (Figuras 5 e 6), sendo isso explicado, possivelmente, pela quantidade de $\mathrm{Na}$ na solução nutritiva proporcionada por essa fonte (Quadro 2).
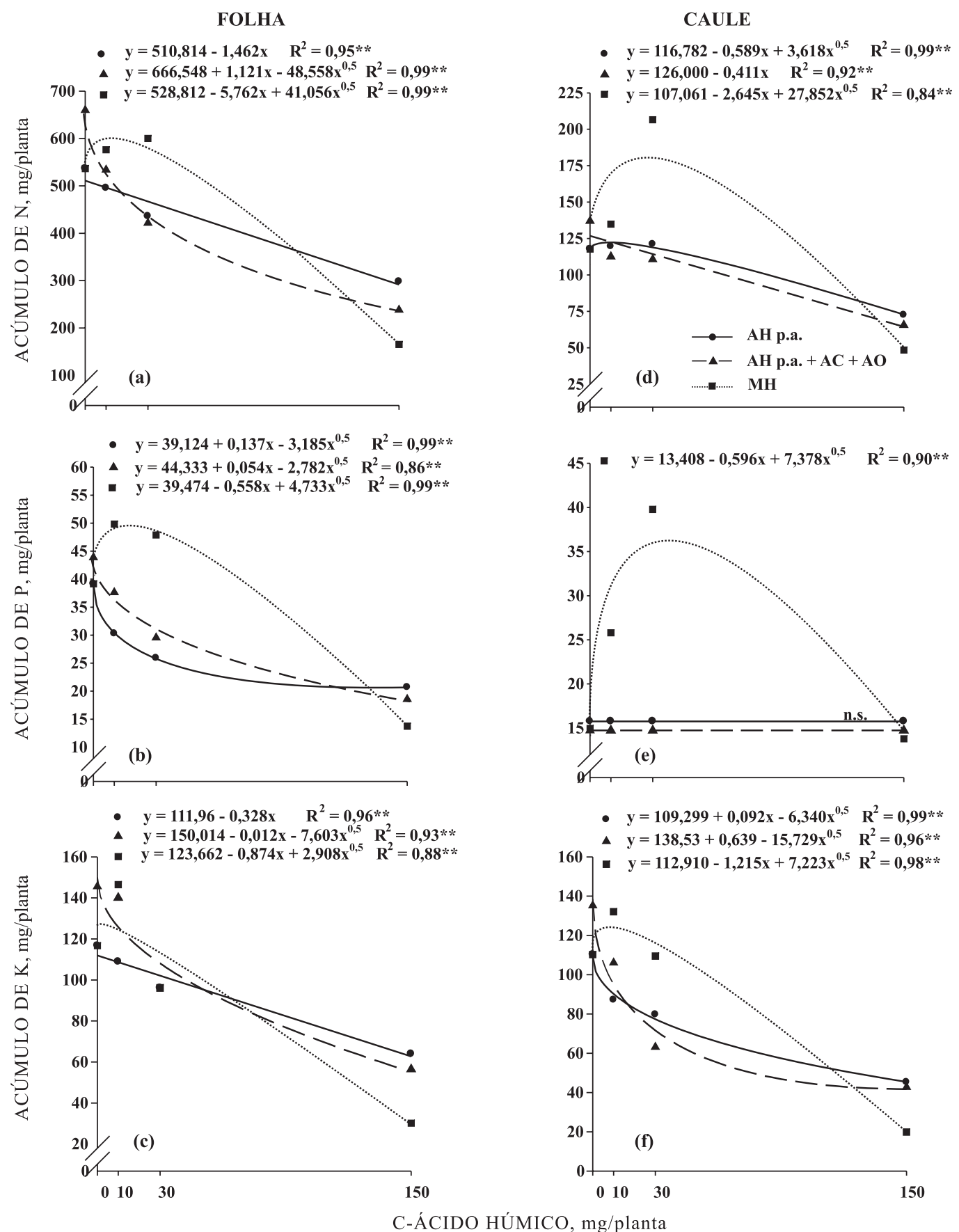

Figura 5. Acúmulo de N, P e K na matéria seca das folhas (a, b, c) e do caule (d, e, f) de mudas de eucalipto, em resposta ao aumento de concentrações de C-ácido húmico em solução nutritiva. AH p.a.: ácido húmico p.a.; MH: material húmico; AC: ácido cítrico; AO: ácido oxálico; ns: não significativo. 
O efeito negativo da aplicação de ácidos húmicos sobre a produção de matéria seca (Figura $2 b, c)$ não alterou o acúmulo de $\mathrm{P}$ nas folhas e no caule, nas menores concentrações de C-ácido húmico do $\mathrm{MH}$ (Figura 5b,e). Aumentos significativos no acúmulo desse nutriente - de aproximadamente $25,4 \%$ nas folhas e $170,3 \%$ no caule - foram obtidos, respectivamente, nas concentrações de 18 e $38 \mathrm{mg} \mathrm{L}^{-1}$ de $\mathrm{C}$-ácido húmico, em relação à menor concentração (0 mg L L ${ }^{-1}$ de C-ácido húmico), ambos com a utilização do MH. Nota-se que o teor de P no meio de cultivo é maior nos tratamentos com o $\mathrm{MH}$, quando comparado àqueles com o $\mathrm{AH}$ p.a. (Quadro 2). Isso explica o maior acúmulo de $\mathrm{P}$, tanto na folha quanto no caule, nas menores concentrações de C-ácido húmico do $\mathrm{MH}$ (Figura 5b,e). A análise de regressão para o acúmulo de $\mathrm{P}$ no caule não foi significativa para os tratamentos $\mathrm{AH}$ p.a. e $\mathrm{AH}$ p.a $+\mathrm{AC}+\mathrm{AO}$, sendo o acúmulo, em média, de 16 e $15 \mathrm{mg} /$ planta, respectivamente (Figura 5e).

$\mathrm{O}$ acúmulo de $\mathrm{K}$ nas folhas e no caule diminuiu com o aumento das concentrações de C-ácido húmico da fonte AH p.a. e pequeno aumento em baixas concentrações de MH (Figura 5c,f), concordando, em parte, com os resultados de Nikbakht et al. (2008), que constataram menor acúmulo de $\mathrm{K}$ nas folhas de gérbera em concentrações mais elevadas de ácidos húmicos $\left(500\right.$ e $\left.1.000 \mathrm{mg} \mathrm{L}^{-1}\right)$ e efeitos não significativos das concentrações de ácidos húmicos nos teores desse nutriente no caule. Ayuso et al. (1996) não verificaram diferenças entre as concentrações das $\mathrm{SHs}$ originadas de diferentes fontes orgânicas (lodo de esgoto, composto orgânico, leonardita, turfa e ácidos húmicos comerciais) nos teores de K na parte aérea de cevada cultivada em solução nutritiva. Rosa et al. (2009) também não encontraram efeitos significativos entre as concentrações de SHs sobre os teores de K na parte aérea de feijão. Diferenças nas concentrações e origem das SHs, na carga de nutrientes agregada ao meio de cultivo pela fonte de ácido húmico e, também, a espécie vegetal utilizada nos diferentes trabalhos mencionados anteriormente, possivelmente, explicariam os efeitos da aplicação de ácido húmico sobre o acúmulo de K, e isso dificulta a comparação dos resultados.

$\mathrm{O}$ acúmulo de $\mathrm{S}$ nas folhas e no caule seguiu o mesmo comportamento do K: redução dos valores com o aumento das concentrações de C-ácido húmico da fonte AH p.a. e pequeno aumento em baixas concentrações de MH (Figura 6c,f). Para os acúmulos de Ca e Mg nas folhas, a análise de regressão revelou comportamento de decréscimo linear e raiz quadrática para as fontes $\mathrm{MH}$ e $\mathrm{AH}$ p.a., respectivamente (Figura 6a,b). No caule, o acúmulo máximo de ambos os nutrientes (Ca e $\mathrm{Mg}$ ) ocorreu até a concentração de aproximadamente 16,8 $\mathrm{mg} \mathrm{L}^{-1}$ de $\mathrm{C}$-ácido húmico do $\mathrm{MH}$, diminuindo a partir desse valor (Figura 6d,e). A presença de $\mathrm{Ca}$ e $\mathrm{Mg}$ no $\mathrm{MH}$ e no $\mathrm{AH}$ p.a. não foi observada por meio de análises laboratoriais
(Quadro 1); dessa forma, a adição desses elementos ao meio de cultivo ocorreu somente pelo fornecimento da solução de Clark (1975). É provável que, em concentrações baixas de C-ácido húmico do $\mathrm{MH}$, tenha ocorrido formação de complexos organometálicos solúveis, que podem ter contribuído para a absorção mais eficiente de $\mathrm{Ca}$ e $\mathrm{Mg}$, refletindo no maior acúmulo desses elementos no caule (Figura 6d,e), já que a planta não foi capaz de transferi-los para as folhas (Figura 6a,b).

\section{Acúmulo de micronutrientes}

$\mathrm{O}$ acúmulo de $\mathrm{Fe}, \mathrm{Zn}$ e $\mathrm{Cu}$ nas folhas e no caule, em geral, foi reduzido com o aumento das concentrações de C-ácido húmico (Figura 7). Embora não se tenha verificado efeito significativo das fontes de ácidos húmicos no acúmulo de $\mathrm{Zn}$ no caule (Figura 7e), observou-se que a adição de $\mathrm{AC}$ e AO, na menor concentração de C-ácido húmico $\left(0 \mathrm{mg} \mathrm{L}^{-1}\right)$, proporcionou acúmulos máximos de $\mathrm{Fe}, \mathrm{Zn}$ e $\mathrm{Cu}$ nas folhas (Figura 7a,b,c). A adição desses ácidos orgânicos de baixa massa molar também promoveu, nas folhas, acúmulo de $\mathrm{Zn}$ cerca de duas vezes maior em relação ao tratamento sem $\mathrm{AC}$ e $\mathrm{AO}$, ambos na concentração de $0 \mathrm{mg} \mathrm{L}^{-1} \mathrm{C}-\mathrm{AH}$ (Figura 7b). Aiken et al. (1985) relatam que um dos principais benefícios dos ácidos húmicos em sistemas agrícolas é sua capacidade de formar complexos metálicos com micronutrientes, embora isso não ocorra na mesma medida para muitos agentes quelantes sintéticos. Os resultados obtidos neste trabalho sugerem que o maior acúmulo de Fe, $\mathrm{Zn}$ e Cu nos tratamentos citados deve-se à absorção e, ou, transferência mais eficiente desses elementos na forma de complexos organometálicos de baixa massa molar para as folhas. Assim, infere-se que o AC e o AO foram mais eficazes na formação de complexos com micronutrientes quando comparados aos ácidos húmicos.

Adani et al. (1998) verificaram que a maior absorção de Fe por plantas de tomate cultivadas em solução nutritiva está relacionada à redução de $\mathrm{Fe}^{3+}$ em $\mathrm{Fe}^{2+}$ pelos ácidos húmicos. Nikbakht et al. (2008) constataram que o teor de $\mathrm{Fe}$ e $\mathrm{Zn}$ nas folhas de gérbera diminuiu na concentração mais elevada de C-ácido húmico $\left(1.000 \mathrm{mg} \mathrm{L}^{-1}\right)$. O efeito das $\mathrm{SHs}$ nas características nutricionais das culturas não é fácil de ser explicado, em razão da natureza complexa e ainda pouco conhecida dessas substâncias. Além disso, as SHs apresentam características distintas, devido à origem do material, ao método de extração e até mesmo às diferentes concentrações em que se encontram (Santos et al., 2008). No presente estudo, o menor acúmulo de micronutrientes, tanto na folha quanto no caule, nas maiores concentrações de C-ácido húmico, possivelmente, se explique pela baixa produção de matéria seca causada pelo excesso de $\mathrm{Na}$ (Quadro 2) e, também, pelas próprias concentrações de C-ácido húmico. 
FOLHA
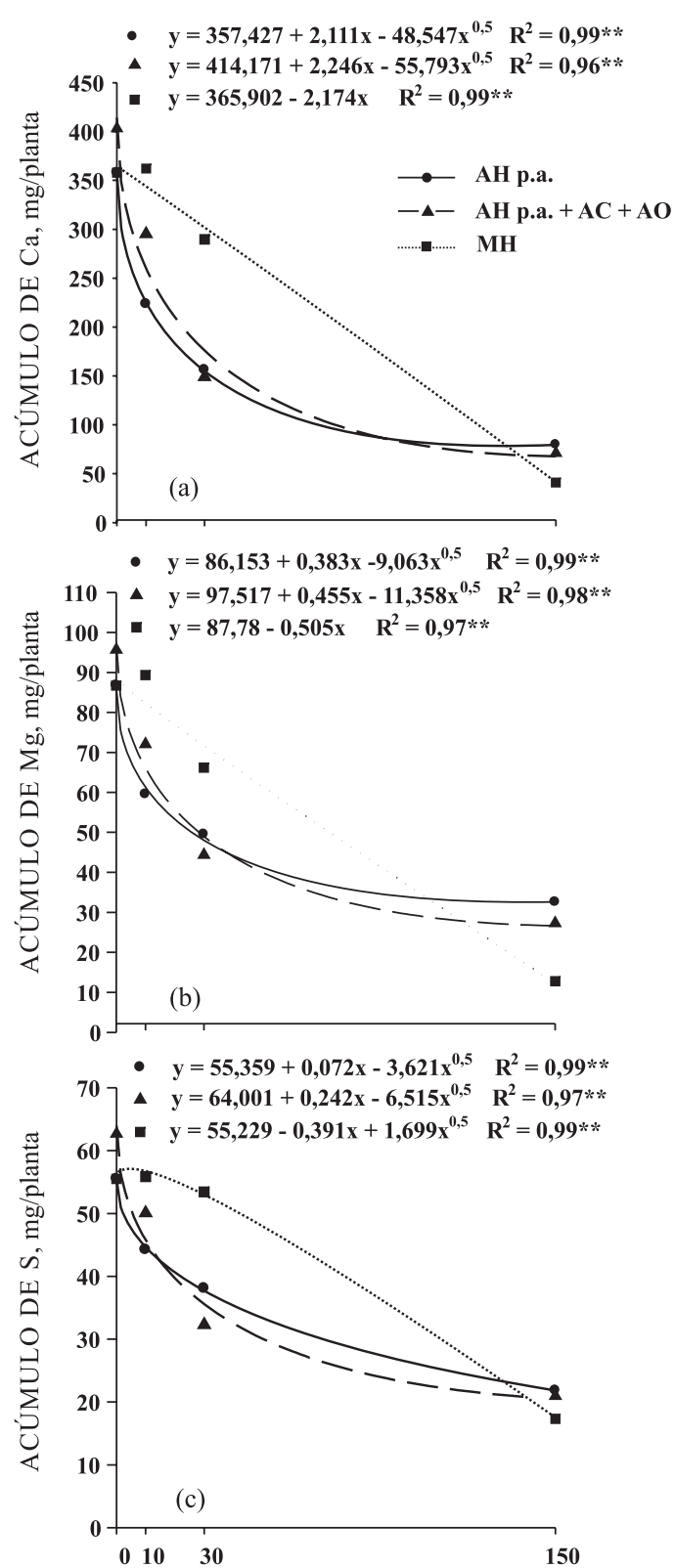

CAULE

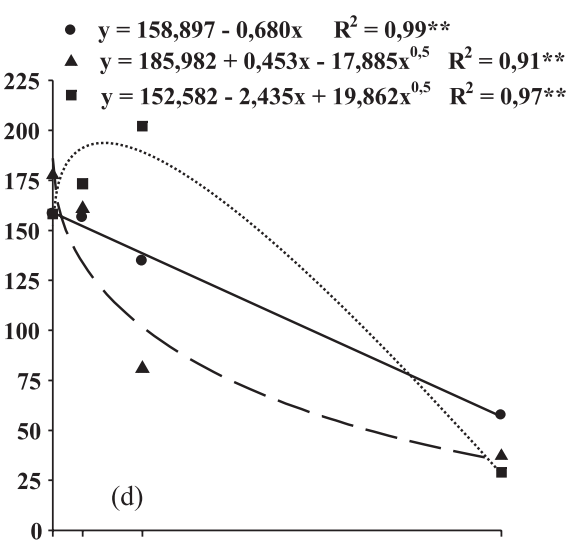

- $y=25,556+0,027 x-1,749 x^{0,5} \quad R^{2}=0,99 * *$

40 ○ $y=28,493+0,109 x-3,179 x^{0,5} R^{2}=0,95^{* *}$

$35-y=24,778-0,384 x+3,166 x^{0,5} R^{2}=0,96 * *$

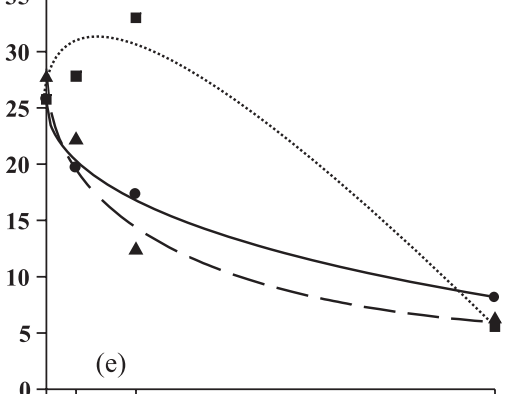

- $y=19,892+0,082 x-2,088 x^{0,5} \quad R^{2}=0,97 * *$

$35 \Delta y=28,843+0,263 x-5,057 x^{0,5} \quad R^{2}=0,99 * *$

$30-$

$y=19,042-0,210 x+1,371 x^{0,5} \quad R^{2}=0,87^{* *}$

C-ÁCIDO HÚMICO, mg/planta

Figura 6. Acúmulo de Ca, Mg e S na matéria seca das folhas (a, b, c) e do caule (d, e, f) de mudas de eucalipto, em resposta ao aumento de concentrações de $\mathrm{C}$-ácido húmico em solução nutritiva. AH p.a.: ácido húmico p.a.; MH: material húmico; AC: ácido cítrico; AO: ácido oxálico.

O acúmulo de B na folha e no caule apresentou variação linear e do tipo raiz quadrática com a aplicação de concentrações de C-ácidos húmicos (Figura 8a,c). A fonte que proporcionou os maiores acúmulos de $\mathrm{B}$, nas menores concentrações de C-ácido húmico, foi o MH, sendo isso, possivelmente, explicado pela maior adição de B por meio deste tratamento, quando comparado à fonte AH p.a. (Quadro 2).

Mesmo com decréscimos na produção de matéria seca (Figura 2), o acúmulo de Mn, para os tratamentos $\mathrm{AH}$ p.a. e $\mathrm{AH}$ p.a $+\mathrm{AC}+\mathrm{AO}$, apresentou pouca variação com o aumento das concentrações de C-ácido húmico. No caule, não houve efeito significativo das concentrações de C-ácido húmico para o tratamento AH p.a.; além disso, a média acumulada de Mn nesse tratamento (514,0 mg/planta) foi aproximadamente cinco vezes maior do que o acúmulo obtido na concentração de $150 \mathrm{mg} \mathrm{L}^{-1}$ de C-ácido húmico do $\mathrm{MH}$ (Figura 8b,d). O baixo acúmulo de $\mathrm{Mn}$, verificado nas maiores concentrações de C-ácido húmico do $\mathrm{MH}$, justifica-se pela baixa produção de matéria seca obtida nesses tratamentos (Figura 2b,c). 

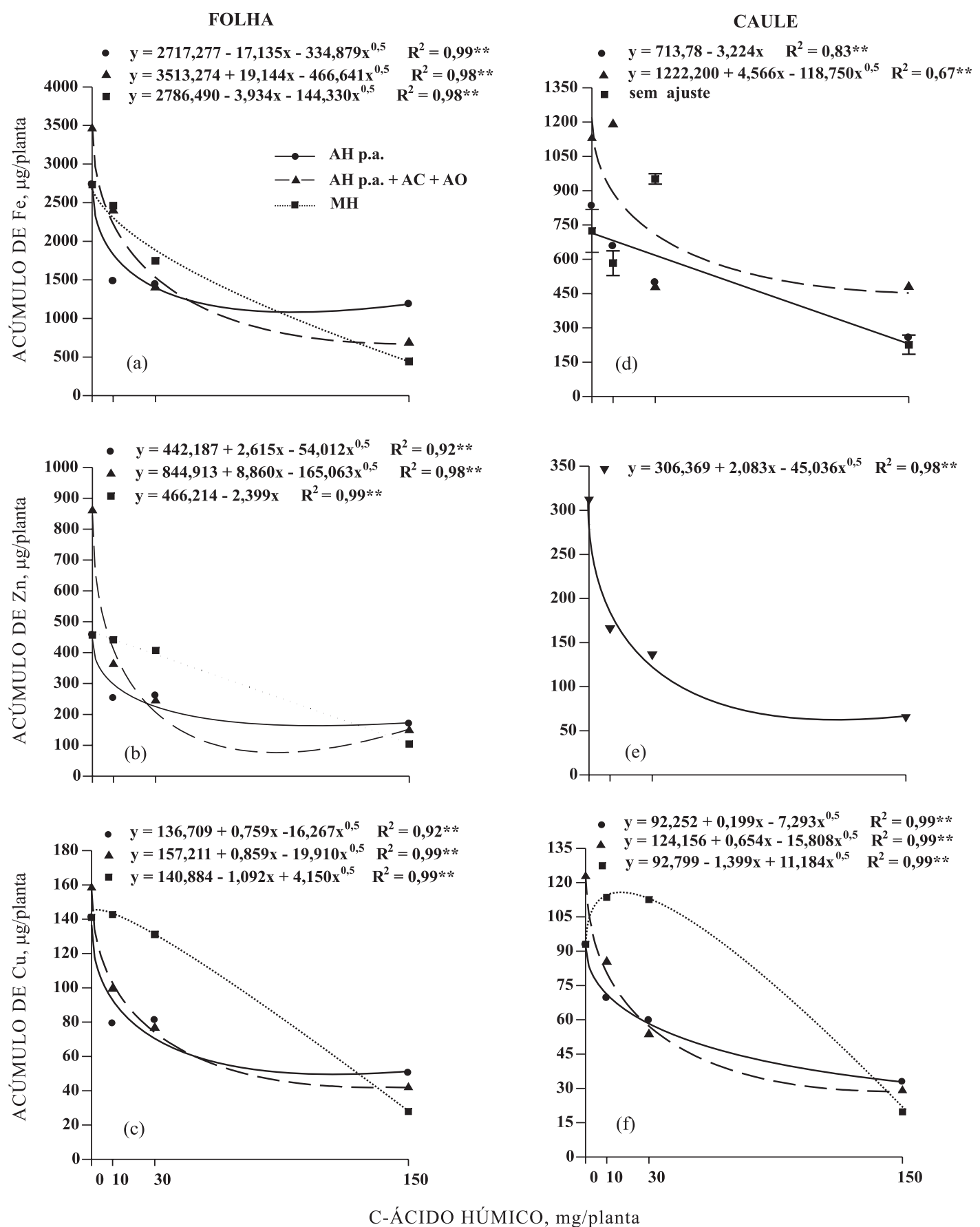

Figura 7. Acúmulo de Fe, Zn e Cu na matéria seca das folhas (a, b, c) e do caule (d, e, f) de mudas de eucalipto em resposta ao aumento de concentrações de C-AH em solução nutritiva. AH p.a.: ácido húmico p.a.; MH: material húmico; AC: ácido cítrico; AO: ácido oxálico.

A adição de $\mathrm{AC}$ e $\mathrm{AO}$, até concentrações de 20,0 e $34,4 \mathrm{mg} \mathrm{L}^{-1}$ de C-ácido húmico, promoveu acúmulos máximos de $\mathrm{Mn}$, respectivamente, na folha e no caule, sendo esse efeito reduzido a partir dessas concentrações. Ressalta-se que o Mn também forma complexos estáveis com ligantes orgânicos (Canellas et al., 2008); portanto, mecanismo semelhante ao proposto para Fe e $\mathrm{Zn}$ pode ocorrer para a absorção de Mn pelas plantas.
Neste estudo, possíveis explicações para o efeito negativo das maiores concentrações de C-ácido húmico nas características nutricionais e de produção de biomassa das mudas também podem estar relacionadas à: condutividade eletrolítica da solução nutritiva acima dos valores normalmente recomendados para plantas jovens de eucalipto; excesso de sódio na solução nutritiva, devido à presença desse elemento químico nos materiais 
FOLHA

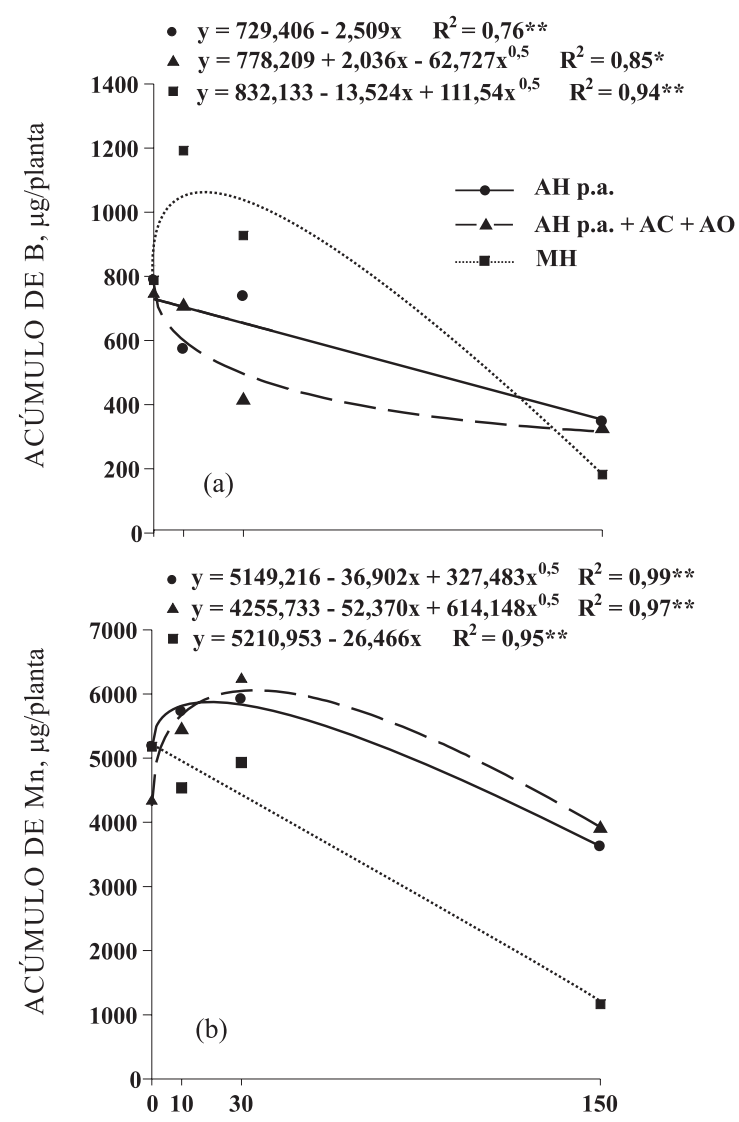

CAULE

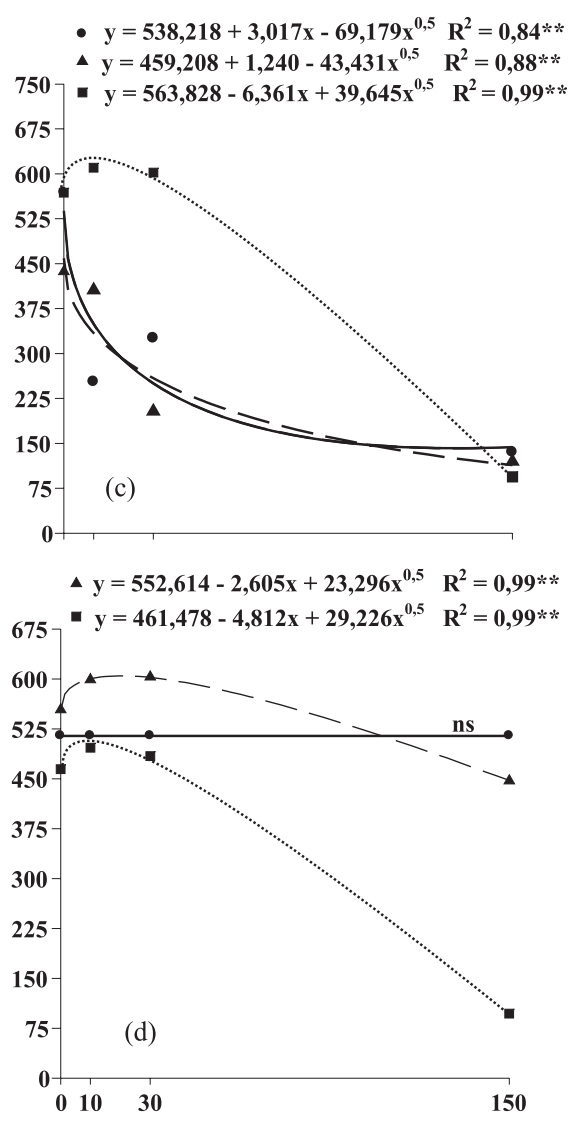

C-ÁCIDO HÚMICO, mg/planta

Figura 8. Acúmulo de B e Mn na matéria seca das folhas (a, b) e do caule (c, d) de mudas de eucalipto em resposta ao aumento de concentrações de C-ácido húmico em solução nutritiva. AH p.a.: ácido húmico p.a.; MH: material húmico; AC: ácido cítrico; AO: ácido oxálico; ns: não significativo.

húmicos testados; formação de complexos organometálicos de elevada massa molar, o que inibiria a entrada do nutriente/complexo nas células das raízes; e formação de complexos organometálicos de grande estabilidade química, o que limitaria a quebra dos complexos na superfície das células radiculares e a aquisição dos nutrientes pelo eucalipto.

\section{CONCLUSÕES}

1. A altura, o diâmetro de caule e a matéria seca de raiz, caule, folhas e total diminuíram com a aplicação de concentrações de C-ácido húmico puro para análise. A utilização do material húmico, em baixas concentrações de C-ácido húmico (0,07$3,8 \mathrm{mg} \mathrm{L}^{-1}$ ), propiciou incrementos, em relação ao tratamento sem adição de ácido húmico, nas produções de matéria seca de raiz, caule, folha e total.

2. A relação raiz/parte aérea foi afetada de forma diferenciada pelos tratamentos, sendo verificada ausência de resposta à aplicação de concentrações de
C-ácido húmico puro para análise, acréscimo linear com o aumento das concentrações de $\mathrm{C}$-ácido húmico do material húmico e resposta do tipo raiz quadrática à aplicação de concentrações de C-ácido húmico juntamente com os ácidos cítrico e oxálico.

3. O material húmico promoveu acúmulos máximos de $\mathrm{N}, \mathrm{P}, \mathrm{K}, \mathrm{S}, \mathrm{Cu}$ e $\mathrm{B}$ nas folhas em concentrações que variaram de 2,8 a $18,0 \mathrm{mg} \mathrm{L}^{-1}$ de C-ácido húmico; no caule, os acúmulos máximos de $\mathrm{N}, \mathrm{P}, \mathrm{K}, \mathrm{Ca}, \mathrm{Mg}, \mathrm{S}, \mathrm{Cu}, \mathrm{B}$ e Mn foram obtidos em faixa de concentração maior do que a observada para as folhas (8,8-39,0 $\left.\mathrm{mg} \mathrm{L}^{-1}\right)$.

4. A adição de ácidos cítrico e oxálico, na ausência de $\mathrm{C}$-ácido húmico puro para análise, aumentou o acúmulo de $\mathrm{Fe}$, nas folhas e no caule, e de $\mathrm{Zn}$ e $\mathrm{Cu}$, nas folhas.

5. O maior acúmulo de alguns nutrientes (principalmente $\mathrm{N}, \mathrm{P}$ e $\mathrm{B}$ ) resultou, em alguns tratamentos, em reduzidos incrementos (2,4 a 9,3\%) nas produções de matéria seca de raiz, folha, caule e total, sendo, assim, não aconselhável, em solução nutritiva, a aplicação das fontes de ácidos húmicos 
utilizadas neste estudo para o cultivo de mudas de eucalipto. Há que se averiguar, em futuros estudos, o efeito de fontes puras e de novas faixas de concentrações de ácido húmico para o eucalipto, bem como a massa molar dos compostos orgânicos e a estabilidade dos complexos organometálicos formados, no sentido de que sejam dirimidas dúvidas quanto à resposta de mudas de eucalipto à adição de $\mathrm{C}$-ácido húmico em solução nutritiva.

\section{AGRADECIMENTOS}

Ao discente de doutorado César Francisco Araujo Junior, pelas valiosas sugestões visando à análise estatística dos dados experimentais; ao aluno de Agronomia Samuel Wanderley Rezende, pela ajuda na condução do estudo e na moagem de materiais vegetais; à doutora Ana Rosa Ribeiro Bastos, pelas valiosas sugestões e pelas correções de aproximações deste estudo; à Fapemig, pelo financiamento de ações de pesquisa deste estudo, por meio do fomento-processo CAG APQ-5362-3. 08/07; e à CAPES, pela concessão da bolsa de Mestrado à primeira autora deste estudo.

\section{LITERATURA CITADA}

ADANI, F.; GENEVINI, P. \& ZACCHEO, P. The effect of commercial humic acid on tomato plant growth and mineral nutrition. J. Plant Nutr., 21:561-575, 1998.

AIKEN, G.R.; MCKNIGHT, D.M.; WERSHAW, R.L. \& MacCARTHY, P. An introduction to humic substances in soil, sediment, and water. In: AIKEN, G.R.; MCKNIGHT, D.M. \& WERSHAW, R.L., eds. Humic substances in soil, sediment and water: Geochemistry, isolation and characterization. New York, John Wiley \& Sons, 1985. 692 .

ATIYEH, R.M.; LEE, S.; EDWARDS, C.A.; ARANCON, N.Q. \& METZGER, J.D. The influence of humic acids derived from earthworm-processed organic wastes on plant growth. Bio. Tecnol., 84:7-14, 2002.

AYUSO, M.; HERNANDEZ, T.; GARCIA, C. \& PASCUAL, J.A. Stimulation of barley growth and nutrient absorption by humic substances originating from various organic materials. Bio. Tecnol., 57:251-257, 1996.

BALDOTTO, L.E.B.; BALDOTTO, M.A.; GIRO, V.B.; CANELLAS, L.P.; OLIVARES, F.L. \& BRESSAN-SMITH, R. Desempenho do abacaxizeiro 'Vitória' em resposta à aplicação de ácidos húmicos durante a aclimatação. R. Bras. Ci. Solo, 33:979-990, 2009.

BENITES, V.M.; MADARI, B. \& MACHADO, P.L.O.A. Extração e fracionamento quantitativo de substâncias húmicas do solo: Um procedimento simplificado de baixo custo. Rio de Janeiro, Embrapa Solos, 2003. 7p. (Comunicado Técnico, 16)
BRUN, G. Pouvoir complexant des matieres humiques effets surl'alimentation minerale des vegetaux. Toulouse, Institut National Polytechnique de Toulouse, 1993. 139p. (Thesis Douctorat)

COSTA, C.N. Efeito das substâncias húmicas no desenvolvimento radicular da cebola, Allium cepa L., e na cinética de absorção de fósforo e potássio. Pelotas, Universidade Federal de Pelotas, 2001. 51p. (Tese de Mestrado)

CANELLAS, L.P. \& FAÇANHA, A.R. Chemical nature of soil humified fractions and their bioactivity. Pesq. Agropec. Bras., 39:233-240, 2004.

CANELLAS, L.P.; OLIVARES, F.L.; OKOROKOVAFACANHA, A.L. \& FACANHA, A.R. Humic acids isolated from earthworm compost enhance root elongation, lateral root emergence, and plasma membrane $\mathrm{H}^{+}$-ATPase activity in maize roots. Plant Physiol., 130:1951-1957, 2002.

CANELLAS, L.P.; ZANDONADI, D.B.; MEDICE, L.O.; OLIVARES, F.L. \& FACANHA, A.R. Bioatividade de substâncias húmicas: Ação sobre o metabolismo e desenvolvimento das plantas. In: CANELLAS, L.P. \& SANTOS, G.A. Humosfera: Tratado preliminar sobre a química das substâncias húmicas. Campos dos Goytacases, UENF, 2005. p.224-243.

CANELLAS, L.P.; ZANDONADI, D.B.; OLIVARES, F.L. \& FAÇANHA, A.R. Efeitos fisiológicos de substâncias húmicas: $\mathrm{O}$ estímulo das $\mathrm{H}^{+}$-ATPases. In: FERNANDES, M.S., ed. Nutrição mineral de plantas. Viçosa, MG, Sociedade Brasileira de Ciência do Solo, 2006. p.176-200.

CHEN, Y. \& AVIAD, T. Effects of humic substances on plant growth. In: MACCARTHY, P., ed. Humic substances in soil and crop sciences: Selected readings. Chicago, CAB, 1990. p.161-187.

CLARK, R.B. Characterization of phosphates of intact maize roots. J. Agric. Food Chem., 23:458-460, 1975.

COOPER, R.J.; LIU, C. \& FISCHER, D.S. Influence of humic substances on rooting and nutrient content of creeping bentgrass. Crop Sci., 38:1639-1644, 1998.

FAÇANHA, A.R.; FAÇANHA, A.S.O.; OLIVARES, F.L.; GURIDI, F.; SANTOS, G.A.; VELLOSO, A.C.X.; BRASIL, F.; SCHRIPSEMA, J.; BRÁZ-FILHO, R.; OLIVEIRA, M. \& CANELLAS, L.P. Bioatividade de ácidos húmicos: Efeitos sobre o desenvolvimento radicular e sobre a bomba de prótons da membrana plasmática. Pesq. Agropec. Bras., 37:1301-1310, 2002.

FERNÁNDEZ-ESCOBAR, R.; BENLLOCH, M. \& BARRANCO, D. Response of olive trees to foliar application of humic substances extracted from leonardite. Sci. Hortic., 66:191200, 1996 .

FERREIRA, D.F. SISVAR software: Versão 4.6. Lavras, DEX/ UFLA, 2003.

GUERRA, J.G.M.; SANTOS, G.A.; SILVA, L.S. \& CAMARGO, F.A.O. Macromoléculas e substâncias húmicas. In: SANTOS, G.A.; SILVA, L.S.; CANELLAS, L.P. \& CAMARGO, F.A.O., eds. Fundamentos da matéria orgânica do solo: Ecossistemas tropicais e subtropicais. Porto Alegre, Metrópole, 2008. p.19-26. 
LOPES, J.L.W.; GUERRINI, I.A.; SAAD, J.C.C. \& SILVA, M.R. Atibutos químicos e físicos de dois substratos para produção de mudas de eucalipto. Cerne, 14:358-367, 2008.

MAGGIONI, A.; VARANINI, Z. \& NARDI, S. Action of soil humic matter on plant roots: Stimulation of ion uptake and effects on $\left(\mathrm{Mg}^{2+}+\mathrm{K}^{+}\right)$ATPase activity. Sci. Total Environ., 62:355-363, 1987.

MALAVOLTA, E.; VITTI, G.C. \& OLIVEIRA, S.A. Avaliação do estado nutricional das plantas: Princípios e aplicações. 2.ed. Piracicaba, POTAFOS, 1997. 319p.

MARQUES JÚNIOR, R.B.; CANELLAS, L.P.; SILVA, L.G. \& OLIVARES, F.L. Promoção de enraizamento de microtoletes de cana-de-açúcar pelo uso conjunto de substâncias húmicas e bactérias diazotróficas endofíticas. R. Bras. Ci. Solo, 32:1121-1128, 2008.

NARDI, S.; PIZZEGHELLO, D.; MUSCOLO, A. \& VIANELLO, A. Physiological effects of humic substances on higher plants. Soil Biol. Biochem., 34:1527-1536, 2002.

NIKBAKHT, A.; KAFI, M.; BABALAR, M.; XIA, Y.P.; LUO, A. \& ETEMADI, N. Effect of humic acid on plant growth, nutrient uptake, and postharvest life of gerbera. J. Plant Nutr., 31:2155-2167, 2008.

RIBEIRO, H.M.; VASCONCELOS, E. \& SANTOS, J.Q. Fertilization of potted geranium with a municipal solid waste compost. Bio. Tecnol., 73:247-249, 2000.

RODDA, M.R.C.; CANELLAS, L.P.; FAÇANHA, A.R.; ZANDONADI, D.B.; GUERRA, J.G.M.; ALMEIDA, D.L. \& SANTOS, G.A. Estímulo no crescimento e na hidrólise de ATP em raízes de alface tratadas com humatos de vermicomposto. I - Efeito da concentração. R. Bras. Ci. Solo, 30:649-656, 2006.
ROSA, C.M.; CASTILHOS, R.M.V.; VAHL, L.C.; CASTILHOS, D.D.; PINTO, L.F.S.; OLIVEIRA, E.S. \& LEAL, O.A. Efeito de substâncias húmicas na cinética de absorção de potássio, crescimento de plantas e concentração de nutrientes em Phaseolus vulgaris L. R. Bras. Ci. Solo, 33:959-967, 2009

SANTOS, G.A.; SILVA, L.S.; CANELLAS, L.P. \& CAMARGO, F.A.O., eds. Fundamentos da matéria orgânica do solo: Ecossistemas tropicais e subtropicais. 2.ed. Porto Alegre, Metrópole, 2008. 636p.

SILVA, R.M.; JABLONSKI, A.; SIEWERDT, L. \& SILVEIRA JÚNIOR, P. Crescimento da parte aérea e do sistema radicular do milho cultivado em solução nutritiva adicionada de substâncias húmicas. R. Bras. Agroci., 5:101110,1999

STEVENSON, F.J. Humus chemistry: Genesis, composition, reactions. New York, John Wiley \& Sons, 1994. 496p.

TURKMEN, O.; DURSUN, A.; TURAN, M. \& ERDINC, C. Calcium and humic acid affect seed germination, growth, and nutrient content of tomato (Lycopersicon esculentum L.) seedlings under saline soil conditions. Acta Agric. Scandinavica Section B-Soil Plant Sci., 54:168-174, 2004.

VAUGHAN, D.; MALCOM, R.E. \& ORD, B.G. Influence of humic substances on biochemical processes in plants. In: VAUGHAN, D. \& MALCOM, R.E. Soil organic matter and biological activity, Dordrecht, Martinus Nijhoff/Junk W, 1985. p.77-108.

YEOMANS, J.C. \& BREMNER, J.M. A rapid and precise method for routine determination of organic carbon in soil. Comm. Soil Sci. Plant Anal., 19:1467-1476, 1988. 